\title{
Condiloma Acuminado Anal com Ovos de Schistosoma mansoni em Paciente HIV-Positivo
}

\author{
Condilomata Acuminata with Schistosoma Eggs \\ in HIV-Positive Patient
}

\author{
FABIANAPIRANI CARNEIRO ${ }^{1}$; MÁRIO A. P. MORAES ${ }^{1}$; MARCOS DE VASCONCELOS CARNEIRO²; \\ LÍVIABRAVO MAIA'; ${ }^{1}$ ALBINO VERÇOSADE MAGALHÃES ${ }^{1}$ \\ ${ }^{1}$ Centro de Anatomia Patológica do Hospital Universitário de Brasília; ${ }^{2}$ Serviço de Gastroenterologia do \\ Hospital das Forças Armadas.
}

CARNEIRO FP; MORAES MAP; CARNEIRO MV; MAIA LB; MAGALHÃES AV. Condiloma Acuminado Anal com Ovos de Schistosoma Mansoni em Paciente HIV-Positivo. Rev bras Coloproct, 2007;27(2): 207-209.

\begin{abstract}
RESUMO: Condiloma acuminado e ovos de Schistosoma são freqüentemente encontrados na região anal, mas não há nenhum caso descrito de associação dessas doenças nessa região. No colo uterino a associação de infecção por HPV (vírus do papiloma humano) e ovos de Schistosoma em paciente HIV (vírus da imunodeficiência humana)-positivo já foi relatada e há evidências de que essa associação possa alterar a história natural dessas doenças. Assim como no colo uterino, é possível que essa interação também ocorra na região anal. Nosso objetivo, portanto, é relatar um caso de condiloma anal em paciente HIV-positivo, que foi submetido a ressecção cirúrgica e que apresentou no exame histopatológico numerosos ovos de Schistosoma mansoni.
\end{abstract}

Descritores: HIV; condiloma acuminado ; ovos de Schistosoma; região perianal; HPV.

\section{INTRODUÇÃO}

Na região anal, lesões associadas ao HPV (vírus do papiloma humano), como condiloma acuminado, neoplasias intraepiteliais e carcinoma anal, estão entre as mais freqüentes, e a incidência dessas lesões é maior em pacientes HIV (vírus da imunodeficiência humana)-positivo ${ }^{1,2,3}$. Ovos de Schistosoma também são comuns nessa região em países como o Brasil em que a esquistossomose é endêmica ${ }^{4}$. Apesar de frequientes na região anal, não foi encontrado nenhum caso descrito de associação entre condiloma acuminado e ovos de Schistosoma nessa região .

A associação de infecção por HPV e ovos de Schistosoma em paciente HIV-positivo já foi relatada no colo uterino e há evidências de que essa associação possa alterar a história natural dessas doenças ${ }^{5,6,7}$. Assim como no colo uterino, é possível que essa interação também ocorra na região anal.
Nosso objetivo, portanto, é relatar um caso de condiloma acuminado anal com ovos Schistosoma em paciente HIV-positivo.

\section{RELATO DE CASO}

Paciente do sexo masculino, de 27 anos, solteiro, procedente de Santa Maria-DF, cabeleireiro, portador do HIV (vírus da imunodeficiência humana) há 8 anos e em uso irregular de zidovudina, didanosina e nevirapina. Há cerca de 3 anos notou crescimento progressivo de tumor em região anal, acompanhado de dor, prurido local, secreção purulenta fétida e sangramento.Tinha antecedentes patológicos de hepatite $\mathrm{B}$, herpes zoster, e pneumocistose pulmonar. Ao exame físico, estava em bom estado geral, corado, hidratado, afebril, acianótico, anictérico; o aparelho cárdio-respiratório e o abdome estavam sem alterações. Na região perianal havia lesão verrucosa de aproxima-

Trabalho realizado no Centro de Anatomia Patológica. Hospital Universitário de Brasília.

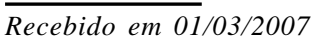

Aceito para publicação em 21/03/2007 
damente $3,0 \mathrm{~cm}$, com presença de orifícios fistulosos, compatível com condiloma. Exames complementares: Leucócitos: 3130 (13\% Eosinófilos, 40\% Segmentados, 40\% Linfócitos, $1 \%$ Basófilos, $6 \%$ Monócitos), CD4: 303 células/ml, CD8: 593 células/ml, carga viral: 338584 cópias/mL $(\log ; 5,53)$. Foi submetido à ressecção da lesão e recebeu alta hospitalar no $2^{\circ}$ dia pós-operatório. O material enviado para exame histopatológico constava, na macroscopia, de vários fragmentos de tecido de transição cutâneo-mucosa com superfície verrucosa, medindo no conjunto $3,5 \times 2,5 \times 2,0 \mathrm{~cm}$. No exame microscópico, o epitélio apresentava papilomatose, acantose, hiperceratose e coilocitose (efeito citopático do HPV). No tecido conjuntivo subepitelial foram observados depósitos intravenulares de múltiplos ovos de Schistosoma mansoni não-viáveis, calcificados e infiltrado inflamatório com predomínio de mononucleares (Figura 1).

\section{DISCUSSÃO}

A morbidade e a mortalidade dos pacientes HIVpositivo têm diminuído significativamente com o uso de anti-retrovirais ${ }^{8}$. Contudo a incidência de condiloma e de outras lesões associadas ao HPV (neoplasias intraepiteliais e carcinoma anal) tem se mantido elevada nos últimos anos nesses pacientes ${ }^{9,10,11,12}$. A maior incidência da infecção pelo HPV em pacientes HIV-positivos está relacionada principalmente à pratica de sexo anal receptivo e ao número de linfócitos $\mathrm{CD} 4+$ menor que 500 células $/ \mathrm{mL}^{13}$. Em nosso caso, o paciente havia interrompido o tratamento e o número de células $\mathrm{CD} 4+$ era de 303 células / $\mu \mathrm{L}$.

Nos pacientes HIV-positivos, os condilomas podem ser gigantes ${ }^{14,15}$, se associados a outras lesões anorretais ${ }^{16}$, e apresentar maior risco de transformação maligna e maiores taxas de recidiva e reinfecção ${ }^{17,18}$. No presente caso, a lesão era gigante $(3 \mathrm{~cm})$, estava associada à fístula e, no exame histopatológico, não foram encontradas áreas de neoplasia intraepitelial, nem invasiva.

Vários estudos têm discutido os efeitos da AIDS na esquistossomose assim como os efeitos da esquistossomose na AIDS ${ }^{19,20}$. Esses estudos mostram que há uma diminuição da excreção de ovos nas fezes e aumento da retenção dos mesmos nos tecidos em pacientes com níveis diminuídos de linfócitos CD4+. Em nosso caso, foram evidenciados numerosos ovos no tecido conjuntivo subepitelial, mas como não havia

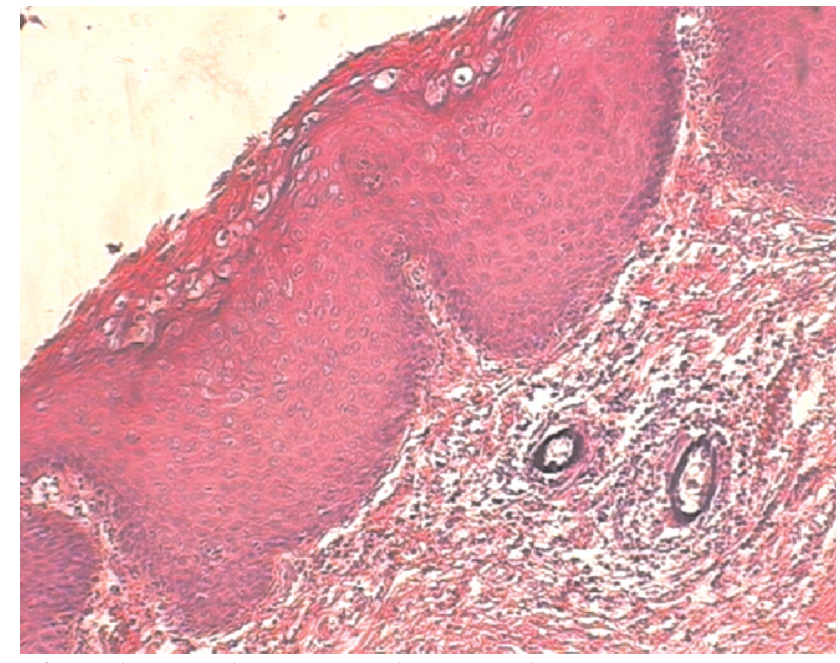

Figura1 - Epitélio com papilomatose, hiperceratose, acantose, coilocitose (efeito citopático do HPV). No tecido conjuntivo sub-epitelial 2 ovos de Schistosoma mansoni não-viáveis calcificados e infiltrado inflamatório com predomínio de mononucleares (HE; x 200).

suspeita clínica de esquistossomose, não foi realizado exame parasitológico de fezes.O único achado sugestivo de parasitose era a eosinofilia no hemograma.

No colo uterino, há hipóteses de que as alterações causadas pela resposta inflamatória e imune aos ovos de Schistosoma possam facilitar a transmissão e a progressão de outras doenças sexualmente transmissíveis como as infecções pelo HPV e HIV. E, portanto, a esquistossomose tornaria os indivíduos mais susceptíveis a essas infecções. Os autores desses estudos sugerem que sejam realizados testes para HIV e HPV nos pacientes com esquistossomose cervical e recomendam investigação e tratamento para esquistossomose cervical nos já infectados por HIV e HPV para evitar recorrência das lesões causadas pelo HPV.

Assim como no colo uterino, é possível que essa interação também ocorra na região anal. Para confirmar essa hipótese deveriam ser realizados estudos que avaliassem a incidência e evolução das infecções causadas pelo HIV e HPV em pacientes com esquistossomose intestinal. Até que essa hipótese seja confirmada, indivíduos com comportamento de risco para infecções pelo HIV e HPV deveriam sempre ser investigados para esquistossomose intestinal principalmente em áreas endêmicas. No caso do nosso paciente, se essa hipótese de interação se confirmasse, o tratamento para esquistossomose seria importante porque evitaria, assim como no colo uterino, a recorrência de lesões associadas ao HPV (condilomas, neoplasia intraepitelial e carcinoma anal). 
ABSTRACT: Condilomata acuminata and Schistosoma eggs are frequently found in the anal region, but there is no report about the association of these diseases in this region. The association of HPV infection and Schistosoma eggs in an HIV-positive patient was found in uterine cervix and there is evidence suggesting that this association can alters the natural history of these diseases. Like in the cervix, it is possible that this interaction also occurs in the anal region. So, we report a case of anal Condilomata acuminata, in an HIV-positive patient, that was ressected and contained on histopathologic examination, multiple Schistosoma eggs.

Key words: HIV; condilomata acuminata; Schistosoma eggs; anal region; HPV.

\section{REFERÊNCIAS}

1. Chin-Hong P, Palefsky JM. The natural history and clinical management of anal HPV disease in HIV-positive men and women. Clin Infect Dis 2002; 35:1127-1134.

2. Nadal SR, Manzione CR, Galvão VM, Salim VR, Speranzini MB. Perianal diseases in HIV-positive patients compared with a seronegative population. Dis Colon Rectum 1999; 42:64954.

3. Yuhan R, Orsay C, DelPino A, Pearl R, Pulvirenti J, Kay S, et al. Anorectal disease in HIV-infected patients. Dis Colon Rectum 1998; 41:1367-70.

4. Rabello AL. Parasitological diagnosis of schistosomiasis mansoni: fecal examination and rectal biopsy. Mem Inst Oswaldo Cruz 1992; 87 Suppl 4:325-31.

5. Mosunjac MB, Tadros T, Beach R, Majmudar B. Cervical schistosomiasis, human papilloma virus (HPV), and human immunodeficiency virus (HIV): a dangerous coexistence or coincidence? Gynecol Oncol 2003; 90:211-214.

6. Poggeensee G, Feldmeier H. Female genital schistosomiasis: facts and hypothesis. Acta Trop 2001; 22:193-210.

7. Prabhakaran VC, Brown LJ. Cervical schistosomiasis and neoplasia in HIV-infected patients. Int J Gynecol Pathol 2004; 23(4):403-4.

8. Murphy E, Collier A, Kalish LA, et al. Highly active antiretroviral therapy decreases mortality and morbidity in patients with advanced HIV disease. Ann Intern Med 2001; 135:17-26.

9. Piketty C, Darragh TM, Heard I, Da Costa M, Bruneval P, Kazatchkine MD, et al. High prevalence of anal squamous intraepithelial lesions in HIV-positive men despite the use of highly active antiretroviral therapy. Sex Transm Dis 2004; 31:96-9.

10. Diamond C, Taylor TH, Aboumrad T, Bringman D, AntonCulver H. Increased incidence of squamous cell anal cancer among men with AIDS in the era of highly active antiretroviral therapy. Sex Transm Dis 2005; 32:314-20.

11. Nadal SR, Manzione CR, Horta SHC, Galvão VM. Comparação das doenças perianais nos doentes HIV+ antes e depois da introdução dos inibidores da protease. Rev bras Coloproct 2001; 21:5-8.

12. Nadal SR, Calore EE, Manzione CR, Assakawa MA, Felix LM, Horta SHC. Incidência de Neoplasias Intraepiteliais Anais em doentes HIV-Positivos portadores de Condilomas Acuminados, comparando período anterior e posterior aos Inibidores da Protease. Rev bras Coloproct 2005; 25(3): 217-222.

13. Critchlow CW, Hawes SE, Kuypers JM, Goldbaum GM, Holmes KK, Surawicz CM, et al. Effect of HIV infection on the natural history of anal human papillomavirus infection. AIDS 1998; 12:1177-84.

14. Safavi A, Gottesmen L, Dailey TH. Anorectal surgery in the HIV+ patient: update. Dis Colon Rectum 1991; 34:229-304.

15. Trombetta LJ, Place RJ. Giant condyloma acuminatum of the anorectum: trends in epidemiology and management: report of a case and review of the literature. Dis Colon Rectum 2001; 44(12):1878-86.

16. Horta SHC, Nadal SR, Manzione CR, Galvão VM. Associação entre Condiloma Acuminado e Fístula Anorretal em Doentes HIV-Positivos. Rev bras Coloproct 2003; 23(3):192-195.

17. Manzione CR, Nadal SR, Calore EE. Postoperative follow up of anal condylomata acuminata in HIV+ patients. Dis Colon Rectum 2003; 46:1358-1365.

18. Orkin BA, Smith LE. Perianal manifestations of HIV infection. Dis Colon Rectum 1992; 35:310-4.

19. Secor WE. Interactions between schistosomiasis and infection with HIV-1. Parasite Immunol 2006; 28(11):597-603.

20. Secor WE, Karanja DM, Colley DG. Interactions between schistosomiasis and human immunodeficiency virus in Western Kenya. Mem Inst Oswaldo Cruz 2004; 99 (5 Suppl 1):93-5.

Endereço para correspondência: FABIANA PIRANI CARNEIRO

Centro de Anatomia Patológica. Hospital Universitário de Brasília. Universidade de Brasília - Brasília, DF.

Via L2 Norte, SGAN 604/605, Módulo C. CEP: 70840-050

Telefone: (61) 3448-5499

E-mail: fabianapirani@hotmail.com 